\title{
KAJIAN PERBANYAKAN BIBIT TEBU (Saccharum officinarum L.) MENGGUNAKAN METODE PENANAMAN SATU MATA (Single Bud Planting)
}

\author{
Study Of Multiple Cane Seeds (Saccharum officinarum L.) \\ Using A Single Bud Planting Method. \\ Ana Amiroh*, Pudyartono, Agus Rianto \\ Program Studi Agroteknologi Fakultas Pertanian \\ Universitas Islam Darul Ulum Lamongan \\ *e-mail: anaamiroh@unisda.ac.id
}

\begin{abstract}
ABSTRAK
Produksi gula bersumber dari areal tebu negara, areal tebu rakyat dan areal tebu swasta. Target swasembada gula dengan program utama bongkar ratoon sehingga perlu bibit dalam jumlah banyak. Metode single bud planting merupakan metode perbanyakan bibit tebu yang menerapkan konsep dan prinsip dari System of Rice Intensification (SRI). Metode ini menerapkan tanaman tebu di pembibitan menggunakan bagal (chip) dengan mata tunggal. Tujuan penelitian ini adalah untuk mengetahui tingkat penangkaran atau multiplikasi bibit tebu. Penelitian dengan menggunakan metode Rancangan Petak-Petak Terbagi (RPPT) yang terdiri dari tiga faktor yaitu: Faktor I: Dosis pupuk (P) dengan 2 level; (P1) pupuk kompos+standar, (P2) pupuk Standar. Faktor II: Varietas tebu (V) dengan 5 level; (V1) varietas PS 881, (V2) PS 882, (V3) PS 862, (V4) PSJK 922, (V5) VMC 76-16. Faktor III: Jarak tanam (A) dengan 3 level; (A1) $20 \mathrm{~cm}$, (A2) 40 $\mathrm{cm}$, (A3) $60 \mathrm{~cm}$. Hasil penelitian bahwa tingkat penangkaran atau multiplikasi bibit tebu terdapat interaksi maupun beda nyata pada perlakuan dosis pupuk, varietas, dan jarak tanam, rata-rata menunjukkan hasil yang baik pada pupuk kompos+standar, perlakuan varietas rata-rata jumlah anakan per rumpun umur 7 BST, pada jenis varietas PS 881 sebesar 6,61 anakan, PS 882 sebesar 6,88 anakan, PS 862 sebesar 6,69 anakan, VMC 76-16 sebesar 6,71 anakan. pada anakan per rumpun pada jarak tanam $60 \mathrm{~cm}$ mencapai 8,16 anakan. pengamatan jumlah mata per batang hasil terbaik terjadi pada varietas PS 862 dengan jarak tanam $60 \mathrm{~cm}$ rata-rata 15 mata per batang, varietas VMC 76-16 rata-rata 15,33 mata per batang.
\end{abstract}

Kata kunci : Swasembada gula, single bud planting, pupuk, varietas tebu, jarak tanam.

\begin{abstract}
Sugar production comes from the country's sugar cane area, the area of sugar cane and the area of private sugar cane. The target of self-sufficiency in sugar with the main program is to dismantle the ratoon so that it needs large quantities of seeds. The single bud planting method is a method of sugarcane seed propagation that applies the concepts and principles of System of Rice Intensification (SRI). This method applies sugar cane in the nursery using a mule (chip) with a single eye. The purpose of this study was to determine the level of breeding or multiplication of sugarcane seedlings. Research using the Split Plot Design Method (RPPT) which consists of three factors, namely: Factor I: Dosage of fertilizer (P) with 2 levels; (P1) Standard compost,$+(P 2)$ Standard fertilizer. Factor II: Sugarcane variety (V) with 5 levels; (V1) PS 881, (V2) PS 882, (V3) PS 862, (V4) PSJK 922, (V5) VMC 76-16. Factor III: Planting distance (A) with 3 levels; (A1) $20 \mathrm{~cm},(A 2) 40 \mathrm{~cm},(A 3) 60 \mathrm{~cm}$. The results showed that the level of breeding or multiplication of sugarcane seedlings had interactions as well as significant differences
\end{abstract}


in the treatment of fertilizer doses, varieties, and spacing, the average showed good results on standard + compost fertilizer, varieties treatment average number of tillers per clump age 7 BST, for the varieties of PS 881 of 6.61 tillers, PS 882 of 6.88 tillers, PS 862 of 6.69 tillers, VMC 76-16 of 6.71 tillers. on tillers per clump at a spacing of $60 \mathrm{~cm}$ reaching 8.16 tillers. observation of the number of eyes per stem the best results occurred in PS 862 varieties with a spacing of $60 \mathrm{~cm}$ on average 15 eyes per stem, varieties of VMC 76-16 an average of 15.33 eyes per stem.

Keywords : Self-sufficiency in sugar, single bud planting, fertilizer, sugarcane varieties, spacing plant.

\section{PENDAHULUAN}

Gula merupakan salah satu kebutuhan pokok bagi penduduk Indonesia. Kebutuhan gula Indonesia diperkirakan mencapai 4 juta ton setiap tahun dengan asumsi jumlah penduduk sekitar 200 juta orang dengan konsumsi gula 20 kg/orang/tahun. Kebutuhan gula sebanyak itu dapat dipenuhi oleh 20 pabrik gula di mana masing-masing pabrik mengelola perkebunan tebu 10.000 ha dengan kapasitas produksi minimum 2 ton gula kristal per hektar. Gula merupakan salah satu komoditas yang ditarget mencapai status swasembada, Tujuan Swasembada gula adalah mampu memenuhi kebutuhan konsumsi gula nasional melalui produksi gula yang bersumber dari areal tebu BUMN, areal tebu rakyat dan areal tebu swasta (Anonymous, 2012a).

Dalam usaha budidaya tebu, penyediaan bibit dengan menggunakan sistem konvensional seringkali terkendala oleh rendahnya produksi bibit dari penangkar, di samping kesehatan dan kemurnian bibit kurang terjamin. Hal ini dikarenakan masa tanam yang lama (6-8 bulan) dan jumlah produksi yang kurang optimal (1:7). Mulai tahun 2010 diperkenalkan sistem tanam tebu dengan sistem Single Bud Planting (SBP) yakni sistem perbanyakan bibit tebu dari batang tebu dalam bentuk stek satu mata, dengan panjang stek $5 \mathrm{~cm}$ dan posisi mata terletak di tengah-tengah dari panjang stek. Keuntungan dari sistem ini antara lain, seleksi bibit semakin baik, proses pembibitan lebih singkat ( 2 - 2,5 bulan), dan pengurangan areal pembibitan sehingga menghemat tempat, serta pertumbuhan anakan serempak (Basuki.2013)

Data empiris di lapangan yang dianalisis berdasarkan sistem dinamik oleh Tim Peneliti Badan Litbang Pertanian menunjukkan bahwa komponen pengungkit peningkatan produksi tebu adalah melalui program bongkar ratoon 10, 15 dan $20 \%$ dari total luas perkebunan tebu rakyat, penataan varietas, pemberian pupuk organik dan perbaikan sistem pengairan. Komponen pengungkit terbesar adalah bongkar ratoon yang diperkirakan mampu meningkatkan produksi gula sebesar $20 \%$ dari produktivitas keprasan (RC) akhir. Pada skenario bongkar ratoon $10 \%$ maka kebutuhan bibit selama tahun 2012 dan 2013 mencapai 512 milyar. Pemerintah mentargetkan swasembada gula 
dengan program utama bongkar ratoon sehingga perlu bibit dalam jumlah banyak. Kementerian Pertanian membuka pada siapa saja yang mampu memproduksi bibit tebu kultur jaringan untuk menjadi pemasok bibit. konteks bibit yang dilihat bukan hanya masalah jumlah saja yang harus dipenuhi, tetapi perlu dicermati mutunya. Mutu tidak hanya menyangkut klon atau varietasnya saja tetapi perlakuan-perlakuan apa yang harus dilakukan untuk menjaga bibit nanti kalau sudah sampai dilapangan mampu beradaptasi dengan cekaman lingkungan, kemasaman tanah, mampu mengatasi serangan hama penyakit dan tumbuhnya seragam. Kondisi pertumbuhan tanaman tebu sangat diperlukan mata tunas yang pertumbuhannya seragam. Mata tunas yang terletak pada ruas yang masih muda dan belum berwarna akan berkecambah lebih cepat daripada yang lebih tua. Akan tetapi semakin ke atas kandungan air yang dimiliki masih tinggi dan makin ke bawah akan makin lama perkecambahannya, hal ini dikarenakan pada ruas bagian bawah tebu terdapat gula sucrose yang tinggi sehingga akan mengakibatkan lamanya perkecambahan (Andayanie, 2013)

Mutu bibit perlu mendapat perhatian ekstra karena ujungnya produktivitas akan ditentukan oleh mutu bibit. Kalau dari segi jumlah tidak ada masalah maka untuk menjaga mutu tidak bisa sembarangan dibuka kepada siapa saja yang bisa memproduksi dan memperbanyak secara vegetatif tanaman tebu. Teknologi yang dipakai P3GI dalam upaya pengadaan bibit tebu dalam jumlah yang besar diantaranya menggunakan metode penanaman satu mata (Single Bud Planting). Teknologi Pembibitan tanaman tebu dengan menggunakan metode Single Bud/Bud Chips Sudah semakin menunjukan keunggulannya, hal ini terlihat jelas pada jumlah anakan jadi yang sangat menggembirakan bagi dunia pertebuan di Indonesia yaitu bisa mencapai 7 s/d 10 anakan jadi yang dihasilkan dari 1 (satu) mata Bud Chips. Selain Keunggulan jumlah anakan yang cukup banyak dalam satu rumpunnya, keunggulan lain dilihat dari besar batang tebu yang dihasilkan sama dengan besar batang tebu yang digunakan untuk bibit atau bahan tanam dengan metode Bud Chips (Anonymous, 2012b).

\section{METODE PENELITIAN}

Bahan yang digunakan dalam penelitian ini yaitu : bibit tebu terdiri dari Varietas PS 881, PS 882, PS 862. PS 92-750 dan VMC 76-16. Pupuk Kompos 1 ton/ha, Pupuk ZA 6 kw/ha, SP-36 2 kw/ha, Herbisida Tarnat dengan bahan aktif Ametrin 80 WP, DMA 6 dengan bahan aktif Dimetyl Amina 825 SL, dan fungisida Benlox dengan bahan aktif benomil 50 WP. Alat-alat yang digunakan yaitu : Cangkul, Lempak, Tugal, Ajir, 
Meteran, Papan Nama, Tali Rafiah, Ember, Jangka Sorong, Hand Sprayer, Kamera, GPS (Global Positioning System), Sabit dan Alat-alat Tulis.

Penelitian menggunakan metode Rancangan Petak - Petak Terbagi (split - split plot design) yang terdiri dari tiga faktor dan setiap faktor terdiri dari 5 level, 3 level, dan 2 level yaitu : Faktor I sebagai petak utama : Dosis Pupuk (P) dengan 2 level: Kompos dan pupuk standar(P1) Dan Pupuk standar (P2), Faktor II sebagai anak petak : Varietas tebu (V) dengan 5 level: V1(Varietas PS 881), V2 (Varietas PS 882), V3 (Varietas PS 862), V4(Varietas PS 92-750) Dan V5(Varietas VMC 76-16). Faktor III sebagai anak-anak petak : jarak tanam (A) dengan 3 level: A1(Jarak tanam $20 \mathrm{~cm})$, A2 (Jarak tanam $40 \mathrm{~cm}$ ). A3 (Jarak tanam $60 \mathrm{~cm})$

Jarak PKP (Petak ke Petak) $100 \mathrm{~cm}$. Dengan kombinasi 3 X 5 X $2=30$ Kombinasi. Jumlah ulangan 30 X $3=90$ ulangan. Jumlah tiap plot sebanyak 3 leng, Jumlah leng : 3 X $90: 270$ leng.

\section{HASIL DAN PEMBAHASAN}

Pertumbuhan tanaman adalah pertambahan ukuran yang dapat diketahui dengan adanya pertambahan panjang, diameter. Untuk mencapai pertumbuhan tanaman yang optimal diperlukan dukungan antara 2 faktor yang mempengarui pertumbuhan yaitu, faktor internal dan faktor eksternal. Faktor internal meliputi gen, benih/bibit, respirasi, sedangkan faktor eksternal meliputi kandungan unsur hara, iklim, cahaya, air, organisme pengganggu tanaman ( OPT ) ( Anindita.2017)

\section{Jumlah Anakan Per Rumpun}

Hasil analisis ragam menunjukkan beda nyata pada perlakuan pupuk, varietas, dan jarak tanam terhadap jumlah anakan per rumpun pada pengamatan umur 1, 2, 3, 4, 5 dan 7 bulan setelah tanam (BST)

Pada tabel 1, dapat dilihat bahwa pengamatan jumlah anakan per rumpun, setelah dilakukan uji lanjutan BNT 5\% menunjukkan adanya pengaruh nyata pada perlakuan pupuk kompos+standar dengan pupuk standar, dimana pemberian pupuk kompos dosis 1 ton/ha yang ditambah pupuk standar yaitu pupuk ZA dosis $600 \mathrm{~kg} / \mathrm{Ha}$, SP-36 Dosis 200 $\mathrm{kg} / \mathrm{Ha}$ memberikan hasil yang baik pada umur 3, 5 BST dan pada umur 1, 2, 4 dan 7 BST kedua perlakuan pupuk tidak menunjukkan adanya beda nyata 
Tabel 1. Rata-rata Jumlah Anakan Per Rumpun pada Pengamatan Umur 1, 5 dan 7 BST.

\begin{tabular}{|c|c|c|c|c|c|c|c|c|c|c|}
\hline \multirow{2}{*}{ Perlakuan } & \multicolumn{10}{|c|}{ Rata-rata Jumlah Anakan per Rumpun Umur } \\
\hline & $1 \mathrm{BST}$ & & $2 \mathrm{BS}$ & & $3 \mathrm{BST}$ & $4 \mathrm{BST}$ & $5 \mathrm{BS}$ & & $7 \mathrm{BS}$ & \\
\hline P1 & 2,52 & $\mathrm{a}$ & 8,70 & $\mathrm{a}$ & $14,81 \mathrm{a}$ & 14,88 a & 11,48 & $\mathrm{a}$ & 6,60 & $\mathrm{a}$ \\
\hline $\mathrm{P} 2$ & 2,23 & a & 7,46 & $\mathrm{a}$ & $12,41 \mathrm{~b}$ & 12,89 a & 9,66 & $\mathrm{~b}$ & 6,35 & $\mathrm{a}$ \\
\hline BNT 5\% & 0,78 & & 4,63 & & 1,47 & 2,15 & 1,32 & & 0,87 & \\
\hline V1 & 2,55 & $\mathrm{a}$ & 8,38 & $a b$ & $13,32 \mathrm{~b}$ & $13,65 \mathrm{~b}$ & 10,31 & bc & 6,61 & a \\
\hline V2 & 2,57 & a & 8,03 & abc & $13,83 \mathrm{ab}$ & $14,02 \mathrm{ab}$ & 10,81 & $a b$ & 6,88 & a \\
\hline V3 & 2,10 & a & 9,09 & a & $15,28 \mathrm{a}$ & $15,51 \mathrm{a}$ & 12,16 & $\mathrm{a}$ & 6,69 & $\mathrm{a}$ \\
\hline V4 & 2,42 & $\mathrm{a}$ & 6,99 & $\mathrm{c}$ & $12,61 \mathrm{~b}$ & $12,61 \mathrm{~b}$ & 9,25 & $\mathrm{c}$ & 5,48 & b \\
\hline V5 & 2,24 & $\mathrm{a}$ & 7,88 & $\mathrm{bc}$ & $13,01 \mathrm{~b}$ & $13,64 \mathrm{~b}$ & 10,31 & bc & 6,71 & $\mathrm{a}$ \\
\hline BNT 5\% & 0,55 & & 1,21 & & 1,96 & 1,69 & 1,55 & & 1,19 & \\
\hline A1 & 2,03 & b & 7,19 & $\mathrm{~b}$ & $11,70 \mathrm{~b}$ & $12,49 \mathrm{~b}$ & 9,15 & $\mathrm{~b}$ & 5,20 & $\mathrm{c}$ \\
\hline A2 & 2,49 & $\mathrm{a}$ & 8,49 & $\mathrm{a}$ & $14,12 \mathrm{a}$ & 14,58 a & 11,33 & $\mathrm{a}$ & 6,12 & b \\
\hline A3 & 2,58 & $\mathrm{a}$ & 8,75 & $\mathrm{a}$ & $15,14 \mathrm{a}$ & $14,86 \mathrm{a}$ & 11,56 & $\mathrm{a}$ & 8,16 & $\mathrm{a}$ \\
\hline BNT 5\% & 0,18 & & 0,74 & & 0,97 & 0,87 & 0,86 & & 0,83 & \\
\hline
\end{tabular}

- Kemudian perlakuan varietas tebu pada pengamatan umur 1 BST kelima macam varietas setelah dilakukan uji lanjutan BNT 5\% terlihat jumlah anakan per rumpun tidak menunjukkan beda nyata. Perbedaan jumlah anakan mulai muncul ketika berumur 2 BST, dimana varietas PS 862 menunjukkan anakan terbanyak sampai umur 5 BST, namun tidak berbeda nyata dengan varietas PS 882. pada umur 1 sampai 7 BST varietas PSJK 922 yang menghasilkan jumlah anakan yang paling sedikit daripada keempat varietas yang lain. Pada kelima varietas perkembangan jumlah anakan berangsur menurun mulai pada umur 5 BST.

Kemudian pada perlakuan jarak tanam, pada umur 1 sampai 5 BST, jarak tanam $40 \mathrm{~cm}$ dan $60 \mathrm{~cm}$ yang menunjukkan hasil yang baik. Dan pada umur 7 BST jarak tanam $60 \mathrm{~cm}$ menunjukkan hasil terbaik. Hal ini membuktikan bahwa perbanyakan bibit dengan metode single bud planting memang menghendaki jarak tanam yang agak renggang agar menghasilkan jumlah anakan yang banyak (Anonymous, 2012b).

\section{Tinggi Batang}

Hasil analisis ragam menunjukkan bahwa terdapat perbedaan nyata antara perlakuan pupuk, varietas, dan jarak tanam terhadap tinggi batang pada pengamatan umur 4, 5 dan 7 BST

Pada tabel 2, dapat dilihat bahwa terdapat perbedaan nyata pada perlakuan pupuk kompos+standar tinggi batang umur 4 BST, varietas tebu dan jarak tanam pada pengamatan tinggi batang umur 4, 5 dan 7 BST, Setelah dilakukan uji lanjutan BNT 5\% terlihat pertumbuhan tinggi batang yang baik terjadi pada perlakuan kompos+standar umur 4 bst, varietas PS 881, PS 862, dan VMC76-16 pada umur 4 dan 5 BST, kemudian pada umur 
7 BST hanya varietas PS 881 yang menunjukkan hasil terbaik. Kemudian hasil baik terjadi pada perlakuan jarak tanam $40 \mathrm{~cm}$ namun tidak berbeda nyata pada jarak tanam $60 \mathrm{~cm}$.

Tabel 2. Rata-rata Tinggi Batang (cm) pada Pengamatan Umur 4, 5 dan 7 BST.

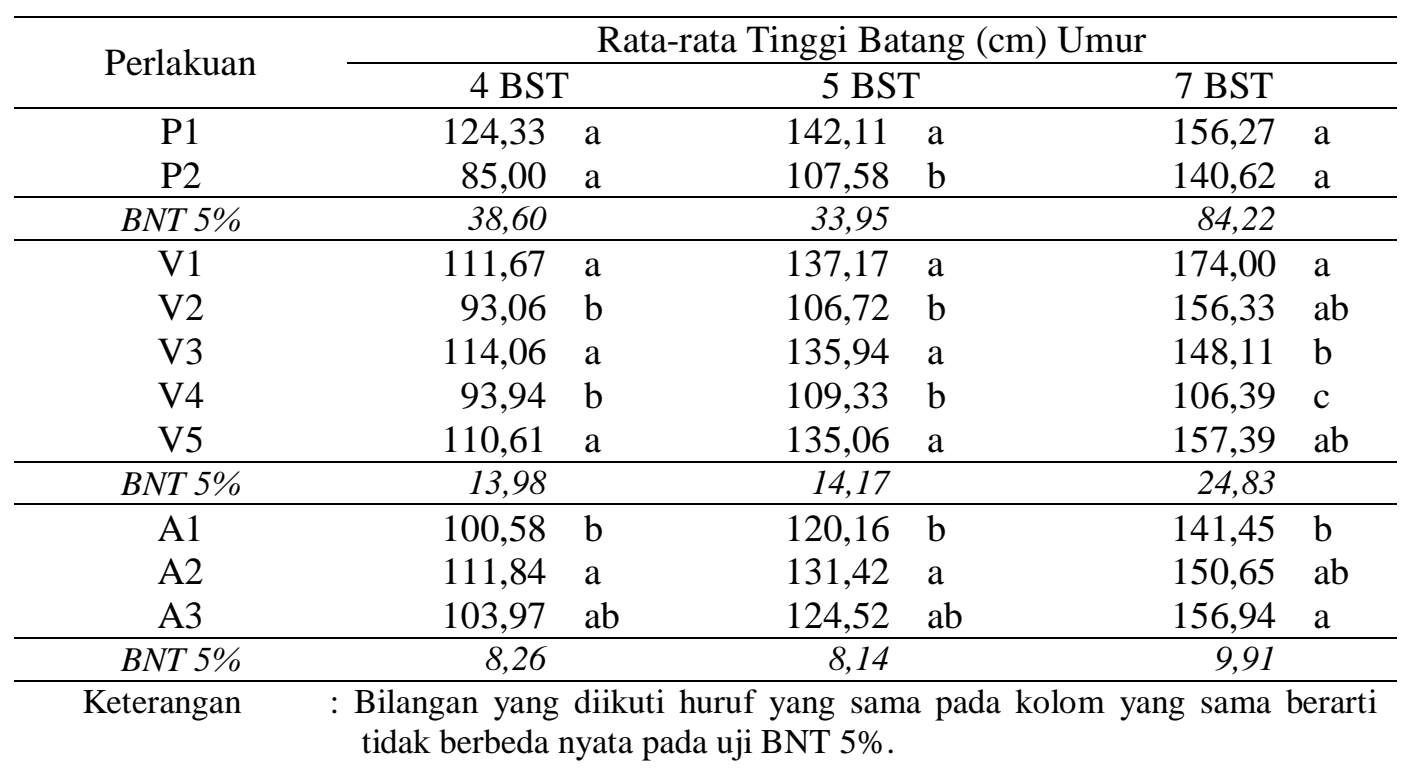

Pada tinggi batang yang terlihat ada kecenderungan bahwa dengan semakin rendahnya dosis pupuk yang diberikan, tinggi batang tebunya akan semakin rendah, begitu juga dengan jenis varietas tebu yang memiliki tajuk daun yang lebih tegak secara umum lebih sesuai dengan lahan kering dan bisa di tanam dengan jarak tanam yang lebih sempit. Dikehendakinya suatu jarak tanam yang tersendiri terhadap varietas diatas nampaknya dapat dijelaskan sehubungan dengan dimilikinya sifat yang berbeda dalam hal penyebaran perakarannya. Penanaman tebu pada jarak tanam rapat memiliki tingkat kepadatan tebu lebih tinggi sehingga terjadi persaingan cahaya dan ruang tumbuh, akibatnya daun tanaman saling menutupi (mutual shadding) untuk bersaing mendapatkan cahaya matahari. Tajuk tanaman yang saling menutupi menyebabkan sebaran cahaya matahari tidak merata, sehingga memungkinkan terjadinya etiolasi yang dikendalikan oleh aktivitas hormon auksin karena tidak mendapatkan cahaya matahari yang cukup (Muttaqin et al.2016) .Selain itu, pada jarak tanam rapat diduga kuantitas dan kualitas cahaya terbatas, menyebabkan fotosintat naik ke atas batang utama dan menjadikan batang meninggi, akibatnya jumlah anakan (Ayele et al., 2014).

Kondisi pertumbuhan tanaman tebu sangat diperlukan mata tunas yang pertumbuhannya seragam. Mata tunas yang terletak pada ruas yang masih muda dan belum berwarna akan berkecambah lebih cepat daripada yang lebih tua. Akan tetapi semakin ke atas kandungan air yang dimiliki masih tinggi dan makin ke bawah akan makin lama perkecambahannya, hal ini dikarenakan pada ruas bagian bawah tebu 
terdapat gula sucrose yang tinggi sehingga akan mengakibatkan lamanya perkecambahan (Andayanie, 2013)

\section{Panjang Ruas per Batang}

Hasil analisis ragam menunjukkan beda nyata pada perlakuan pemberian pupuk, varietas, dan jarak tanam terhadap panjang ruas pada pengamatan umur 4, 5 dan 7 bulan setelah tanam (BST)

Tabel 3. Rata-rata Panjang Ruas (cm) pada Pengamatan Umur 4, 5 dan 7 BST.

\begin{tabular}{|c|c|c|c|c|c|c|}
\hline \multirow{2}{*}{ Perlakuan } & \multicolumn{6}{|c|}{ Rata-rata Panjang Ruas (cm) Umur } \\
\hline & $4 \mathrm{BST}$ & & $5 \mathrm{BS}$ & & 7 BST & \\
\hline P1 & 7,91 & $\mathrm{a}$ & 9,82 & $\mathrm{a}$ & 9,38 & $\mathrm{a}$ \\
\hline P2 & 7,34 & $\mathrm{a}$ & 9,53 & $\mathrm{a}$ & 10,00 & $\mathrm{a}$ \\
\hline BNT 5\% & 5,33 & & 0,95 & & 3,72 & \\
\hline V1 & 8,16 & $a b$ & 11,19 & a & 10,64 & $\mathrm{a}$ \\
\hline V2 & 6,03 & $\mathrm{c}$ & 8,98 & bc & 10,83 & $\mathrm{a}$ \\
\hline V3 & 8,92 & $\mathrm{a}$ & 10,71 & $a b$ & 9,63 & a \\
\hline V4 & 6,60 & $\mathrm{bc}$ & 8,03 & $\mathrm{c}$ & 7,73 & $\mathrm{~b}$ \\
\hline V5 & 8,41 & $a b$ & 9,45 & $a b c$ & 9,61 & a \\
\hline BNT 5\% & 1,83 & & 1,81 & & 1,88 & \\
\hline A1 & 7,93 & $\mathrm{a}$ & 9,78 & $\mathrm{a}$ & 9,41 & $\mathrm{a}$ \\
\hline A2 & 7,45 & $\mathrm{a}$ & 9,34 & $\mathrm{a}$ & 9,80 & $\mathrm{a}$ \\
\hline A3 & 7,89 & $\mathrm{a}$ & 10,14 & a & 10,13 & $\mathrm{a}$ \\
\hline BNT 5\% & 0,85 & & 1,16 & & 0,93 & \\
\hline
\end{tabular}

Keterangan : Bilangan yang diikuti huruf yang sama pada kolom yang sama berarti tidak berbeda nyata pada uji BNT 5\%.

Tabel 3, pada pengamatan panjang ruas umur 4, 5 dan 7 BST menunjukkan adanya beda nyata hanya pada macam varietas, sedangkan pada perlakuan macam pupuk dan jarak tanam tidak berbeda nyata. Terlihat bahwa panjang ruas menunjukkan hasil yang baik pada ketiga varietas, diantaranya varietas PS 881, PS 862, dan varietas VMC 76-16, namun pada jenis varietas VMC 76-16 menunjukkan tidak berbeda nyata dengan varietas PS 882 dan PSJK 922. Kemudian pada pengamatan pada umur 7 bulan hanya varietas PSJK 922 yang menunjukkan nilai terendah daripada keempat veriatas yang lain. Menurut Pawirosemadi (2011) bahwa kompos mengandung hampir seluruh unsur hara yang diperlukan tanaman, namun dalam jumlah yang kecil sehingga biasanya tidak memenuhi jumlah yang diperlukan tanaman. Pada umumnya penggunaan kompos lebih ditekankan untuk perbaikan sifat fisik tanah. Sehingga pupuk kompos dikombinasikan dengan pupuk standar, diduga varietas PSJK 922 tersebut memiliki respon yang lambat terhadap penyerapan unsur hara daripada keempat varietas yang lain. 


\section{Jumlah Mata Per Batang.}

Hasil analisis ragam menunjukkan bahwa terdapat beda nyata antara perlakuan pemberian pupuk, varietas dan jarak tanam terhadap jumlah mata per batang pada umur 4 dan 5 BST

Tabel 4. Rata-rata Jumlah Mata per Batang Umur pada Pengamatan Umur 4 dan 5 BST.

\begin{tabular}{|c|c|c|c|c|}
\hline \multirow{2}{*}{ Perlakuan } & \multicolumn{4}{|c|}{ Rata-rata Jumlah Mata per Batang Umur } \\
\hline & $4 \mathrm{BS}$ & & $5 \mathrm{BS}$ & \\
\hline $\mathrm{P} 1$ & 8,44 & $\mathrm{a}$ & 9,67 & $\mathrm{a}$ \\
\hline P2 & 5,93 & $\mathrm{~b}$ & 7,42 & $\mathrm{~b}$ \\
\hline$B N T 5 \%$ & 2,21 & & 1,85 & \\
\hline V1 & 7,50 & $\mathrm{~b}$ & 9,72 & $\mathrm{a}$ \\
\hline V2 & 6,17 & $\mathrm{~d}$ & 7,06 & $\mathrm{~b}$ \\
\hline V3 & 8,78 & $\mathrm{a}$ & 9,67 & $\mathrm{a}$ \\
\hline V4 & 6,22 & $\mathrm{~cd}$ & 7,28 & $\mathrm{~b}$ \\
\hline V5 & 7,28 & bc & 9,00 & $\mathrm{a}$ \\
\hline$B N T 5 \%$ & 1,08 & & 1,00 & \\
\hline A1 & 6,90 & $\mathrm{~b}$ & 8,23 & $\mathrm{~b}$ \\
\hline A2 & 7,74 & $\mathrm{a}$ & 9,06 & $\mathrm{a}$ \\
\hline A3 & 7,19 & $a b$ & 8,45 & $\mathrm{~b}$ \\
\hline BNT 5\% & 0,58 & & 0,56 & \\
\hline
\end{tabular}

Keterangan : Bilangan yang diikuti huruf yang sama pada kolom yang sama berarti tidak berbeda nyata pada uji BNT $5 \%$.

Pada tabel 4, menunjukkan bahwa adanya beda nyata pada perlakuan pupuk, perlakuan varietas, dan perlakuan jarak tanam, pada perlakuan pupuk hasil terbaik setelah dilakukan uji lanjutan BNT 5\% terjadi pada penggunaan pupuk kompos+standar pada umur 4 dan 5 BST, dan untuk jenis varietas pada umur 4 BST menunjukkan bahwa jumlah mata terbanyak terjadi pada varietas PS 862, dan pada umur 5 BST pada varietas PS 881, PS 862 dan VMC 76-16 menunjukkan hasil terbaik. kemudian untuk jarak tanam beda nyata terbaik terjadi pada jarak tanam $40 \mathrm{~cm}$ pada umur 4 dan 5 BST, namun jarak tanam 60 $\mathrm{cm}$ tidak berbeda nyata dengan jarak tanam $40 \mathrm{~cm}$ pada umur 4 BST .

Hasil analisis ragam berikutnya menunjukkan bahwa terdapat interaksi antara perlakuan pemberian pupuk dan jarak tanam terhadap jumlah mata per batang pada umur 7 BST

Pada tabel 5, pengamatan jumlah mata per batang pada umur 7 bulan terlihat bahwa interaksi terbaik setelah dilakukan uji lanjutan BNT 5\% terjadi pada perlakuan pupuk kompos+standar dengan jarak tanam $20 \mathrm{~cm}$, namun tidak berbeda nyata pada interaksi pupuk kompos+standar dengan jarak tanam $40 \mathrm{~cm}$. 
Tabel 5. Rata-rata jumlah mata per batang pada Pengamatan Umur 7 BST.

\begin{tabular}{cr}
\hline Interaksi & Rata-rata jumlah mata per batang Umur 7 BST \\
\hline P1A1 & $14,33 \quad \mathrm{a}$ \\
P1A2 & $13,67 \quad$ ab \\
P1A3 & $12,33 \quad \mathrm{c}$ \\
P2A1 & $12,80 \quad \mathrm{bc}$ \\
P2A2 & $12,53 \quad \mathrm{c}$ \\
P2A3 & $13,20 \quad$ bc \\
\hline
\end{tabular}

Keterangan : Bilangan yang diikuti huruf yang sama pada kolom yang sama berarti tidak berbeda nyata pada uji BNT 5\%.

Pada hasil jumlah anakan per rumpun,pemberian pupuk kompos dosis 1 ton/ha yang ditambah pupuk standar yaitu pupuk ZA dosis $600 \mathrm{~kg} / \mathrm{Ha}$, SP-36 dosis $200 \mathrm{~kg} / \mathrm{Ha}$ memberikan hasil yang baik.Varietas PSJK 922 yang menghasilkan jumlah anakan paling sedikit daripada keempat varietas yang lain. Jarak tanam $60 \mathrm{~cm}$ menunjukkan hasil terbaik.Pada tinggi tunas dosis pupuk kompos+standar, varietas PS 862 dan jarak tanam $40 \mathrm{~cm}$.Pada tinggi batang varietas PS 881 yang menunjukkan hasil terbaik dengan jarak tanam $40 \mathrm{~cm}$ namun tidak berbeda nyata pada jarak tanam $60 \mathrm{~cm}$.Anakan per rumpun pada jarak tanam $60 \mathrm{~cm}$ umur 7 BST mencapai rata-rata 8,16 anakan.

Pada pengamatan diameter tunas pada perlakuan pupuk kompos+standar berinteraksi dengan jarak tanam 20, 40 maupun $60 \mathrm{~cm}$ perlakuan pupuk standar+kompos menunjukkan interaksi terbaik pada pada varietas PS 862. Interaksi pada pengamatan diameter batang perlakuan terbaik terdapat pada dosis pupuk kompos+standar yang berinteraksi dengan varietas PS 862 dan dengan jarak tanam $60 \mathrm{~cm}$. Pengamatan panjang ruas per batang varietas PSJK 922 menunjukkan nilai terendah daripada keempat veriatas yang lain.Pada varietas PS 862 dengan jarak tanam $60 \mathrm{~cm}$ rata-rata menghasilkan 15 mata per batang, varietas VMC 76-16 rata-rata 15,33 mata per batang.

\section{KESIMPULAN}

Berdasarkan pengamatan mulai dari umur 1,2,3,4,5 dan 7 BST pada pelaksanaan penelitian tebu dengan judul "Perbanyakan Bibit Tebu (Saccharum Officinarum L.) Menggunakan Metode Penanaman Satu Mata (Single Bud Planting)”. Maka dapat disimpulkan bahwa tingkat penangkaran atau multiplikasi bibit tebu terdapat interaksi maupun beda nyata pada perlakuan dosis pupuk, varietas, dan jarak tanam, rata-rata menunjukkan hasil yang baik pada pupuk kompos+standar, perlakuan varietas rata-rata jumlah anakan per rumpun umur 7 BST, pada jenis varietas PS 881 sebesar 6,61 anakan, PS 882 sebesar 6,88 anakan, PS 862 sebesar 6,69 anakan, VMC 76-16 sebesar 
6,71 anakan. pada anakan per rumpun pada jarak tanam $60 \mathrm{~cm}$ mencapai 8,16 anakan. pengamatan jumlah mata per batang hasil terbaik terjadi pada varietas PS 862 dengan jarak tanam $60 \mathrm{~cm}$ rata-rata 15 mata per batang, varietas VMC 76-16 rata-rata 15,33 mata per batang.

\section{DAFTAR PUSTAKA}

Andayanie, W. R. 2013. Penggunaan Nomor Mata Tunas dan Jenis Herbisida Pada Pertumbuhan Awal Tanaman Tebu (Sacharum officinarum L.) Fakultas Pertanian Universitas Merdeka, Madiun. Agritek 14 (1) : 1-6

Anonymous, 2012a. http://panorama76news.blogspot.com/2012/05/teknologi-bud-chipssemakin-menunjukan.html. Diakses pada 29 April 2018 jam 12.40 wib.

Anonymous, 2012b. http://panorama76news.blogspot.com/2012/05/teknologi-bud-chipssemakin-menunjukan.html. Diakses pada 30 April 2018 jam 12.40 wib.

Basuki. 2013. Pengaruh Cendawan Mikoriza Arbuskula (CMA) Terhadap Karakteristik Agronomi Tanaman Tebu Sistem Tanam Bagal Satu. J. Menara Perkebunan. 81 (2) : 49-53

Devina C.A. 2017 .Pertumbuhan Bibit Satu Mata Tunas Yang Berasal Dari Nomor Mata Tunas Berbeda Pada Tanaman Tebu ( Saccaharum officinarum L. ) Varietas Bululawang Dan PS862. Jurnal Produksi Tanaman Vol. 5 No. 3, Maret 2017: 451 - 459 ISSN: 2527-8452

Getaneh, A., N. Ayele, T. Negi and Y. Mekuanent. 2014. Effect Number of Buds per Sett and Sett Spacing on Yield of Sugarcane at Metahara Sugar Estate. The J. of Agriculture and Natural Resources Sciences. 1 (4) : 238-244

Khuluq, A. D. dan Ruly H. 2014. Peningkatan Produktivitas dan Rendemen Melalui Rekayasa Fisiologis Pertunasan. J. Presfektif. 1 (13) : 13-24

Muttaqin. L.2016. Pengaruh Jarak Tanam terhadap Pertumbuhan Awal Lima Klon Tebu (Saccharum oficinarum L.) Asal Bibit Mata Tunas Tunggal di Lahan Kering Alfisol. Vegetalika. 5(2): 49-61

Pawirosemadi M. 2011. Dasar-dasar Teknologi Budidaya Tebu dan Pengolahan Hasilnya. Sujanto S, editor. Malang (ID): IKIP Malang

Putri, A. D., Sudiarso dan T. Islami. 2013. Pengaruh Komposisi Media Tanam Pada Teknik Bud Chip Tiga Varietas Tebu (Saccharum officinarum L.). J. Produksi Tanaman. 1 (1) : $16-23$

Rini SF .2012. Teknologi Percepatan Pembibitan Tebu Dengan Bud Chip. Di unduh dari: http://ditjenbun. Deptan.go.id/bbp2tpsur/images/stories/perbenihan/ bud chip puslit.pdf. [13 April 2018]. 